\title{
Electrocardiographic monitoring in healthy young adult outpatients: mandatory or optional?
}

Ibrahim Zabani MD, Himat Vaghadia MHSc FRCPC FFARCS, * Colin R. Chilvers BMED DA (UK), Pamela M. Merrick BSN

Purpose: To determine the incidence and duration of ECG abnormalities in healthy adults during short duration outpatient surgery and their relationship to important clinical events.

Method: In 381, ASA Class I, day surgery patients undergoing short surgical procedures the ECG was monitored prospectively for evidence of abnormalities. The attending anaesthetist administered the anaesthetic and made all clinical decisions while relying on routine monitors ( $E C G$, oximeter, $B$, capnometer, oxygen analyser, low pressure alarm and anaesthetic gas monitors). Intra-operative events of clinical significance (e.g., light anaesthesia, regurgitation, coughing, hypotension, arterial desaturation, hiccoughs etc), ECG abnormalities and their duration were documented.

Results: Electrocardiographic abnormalities were detected in $21 \%$ of patients as follows: sinus tachycardia ( $1 \%$ ), artifacts $(7 \%)$, premature atrial contractions $(1.6 \%)$, lead disconnects $(1 \%)$, sinus bradycardia $(0.5 \%)$ and premature ventricular contractions (0.3\%). All abnormalities resolved spontaneously within three minutes. Intra-operative incidents of consequence occurred in only $2.6 \%$ : light anaesthesia (5), arterial desaturation $>5 \%$ (2), hypotension (1), hiccough (I) and regurgitation (I). All incidents were detected clinically and by pulse oximetry. The ECG did not detect any of the incidents and was normal during the events.

Conclusion: Routine ECG monitoring did not detect intra-operative incidents in healthy adults during short outpatient procedures. Detected ECG abnormalities were benign and resolved spontaneously within three minutes. Firm conclusions as to the safety implications of withdrawing ECG monitoring cannot be drawn from this study. Guidelines may need to be reviewed to determine whether ECG monitoring in such cases should be optional rather than mandatory.

Objectif : Déterminer l'incidence et la durée des anomalies de l'ECG chez des adultes en bonne santé durant des chirurgies ambulatoires de courte durée, et la relation entre ces anomalies et des événements cliniques importants.

Méthode : Chez 381 patients de chirurgie ambulatoire, de classe I de l'ASA, subissant des procédures chirurgicales courtes, l'ECG a été monitoré de façon prospective à la recherche d'anomalies. L'anesthésiste responsable du patient administrait l'anesthésie et prenait toutes les décisions cliniques selon les informations fournies par les moniteurs usuels, soit l'ECG, le saturomètre, la mesure de la pression artérielle, le capnomètre, l'oxymètre, l'analyseur de gaz anesthésiques et le système d'alarme de basse pression. On a documenté les anomalies à l'ECG et leur durée, de même que les événements peropératoires ayant une signification clinique ( $\mathrm{vg}$ anesthésie légère, régurgitation, toux, hypotension, désaturation, hoquet, etc.)

Résultats : Des anomalies électrocadiographiques ont été détectées chez $21 \%$ des patients : tachycardie sinusale $11 \%$, artéfacts $7 \%$, extrasystoles auriculaires $1,6 \%$, déconnection des électrodes $1 \%$, bradycardie sinusale $0,5 \%$ et extrasystoles ventriculaires $0,3 \%$. Toutes les anomalies se sont corrigées spontanément en moins de trois minutes. Des incidents peropératoires significatifs sont survenus dans $2,6 \%$ des cas seulement : anesthésie légère 5 patients, désaturation de $\geq 5 \% 2$ patients, hypotension I patient, hoquet I patient et régurgitation I patient. Tous les incidents ont été détectés cliniquement et par le saturomètre. L'ECG est demeuré normal durant tous ces incidents et n'a pas permis d'en détecter un seul.

Conclusion : Le monitorage de routine de l'ECG n'a pas permis de détecter d'incidents peropératoires chez des adultes en bonne santé opérés en chirurgie ambulatoire pour des procédures courtes. Les anomalies détectées étaient bénignes et se sont toutes résolues en deça de 3 minutes. Des conclusions définitives concernant les implications quant à la sécurité de cesser le monitorage de l'ECG ne peuvent être tirées de cette étude. Les lignes de conduite pourraient être revues et, dans ces cas, l'ECG pourrait devenir facultatif plutôt qu'essentiel.

From the Section of Ambulatory Anaesthesia, Department of Anaesthesia, Vancouver Hospital and Health Sciences Centre and The Department of Health Care and Epidemiology, University of British Columbia, Vancouver, British Columbia, Canada. Address correspondence to: Dr. Himat Vaghadia, Department of Anaesthesia, Faculty of Medicine, 910- West 10th Avenue, Room 3200, Vancoúver, B.C. Canada V5Z 4E3; E-mail: hvaghadi@vanhosp.bc.ca Accepted for publication January 31, 1998. 


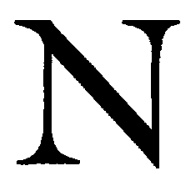

ORTH American guidelines for monitoring stipulate that the ECG is a routine monitor that is required in all patients..$^{1,2}$ Short acting anaesthetics such as propofol are widely employed in most ambulatory facilities and are free of major cardiovascular effects in healthy young patients. ${ }^{3}$ Recently, the Australian Incident Monitoring Study (AIMS) found that the ECG had poor sensitivity for the detection of serious physiological problems and it was suggested that an ECG monitor should always be available but need not be used in healthy young patients unless specifically indicated. ${ }^{4}$

The purpose of this study was to study prospectively the incidence and duration of ECG abnormalities and their relationship to intra-operative incidents of clinical significance during anaesthesia for short outpatient procedures in healthy young adults.

\section{Methods}

After institutional ethics approval 381 healthy ASA I adults, with no past history of cardiac problems, under going short ( $<30 \mathrm{~min}$ ) outpatient procedures (e.g., therapeutic abortion, cystoscopy and minor vulval surgery) were studied prospectively. Patient consent was not required by our Ethics Board because all patients were routinely monitored according to current guidelines. Upon arrival in the operating room all patients had routine monitors applied (ECG, BP, oximeter) and an intravenous infusion of crystalloid was in progress. Anaesthesia technique was standardised and consisted of induction with $1-2 \mathrm{mg} \cdot \mathrm{kg}^{-1}$ propofol and $1-2 \mu \mathrm{g} \cdot \mathrm{kg}^{-1}$ fentanyl. Anaesthesia was maintained with propofol titrated to clinical effect and nitrous oxide $50-70 \%$ in oxygen. Inhalational vapours were not used. The attending anaesthetist was not blinded to the ECG in keeping with the Ethics Board requirements and administered the anaesthetic based on clinical signs (e.g., eye lash reflexes, movement, breathing pattern, heart rate and blood pressure) and information available from the monitors. The principal investigator continuously monitored the ECG during the procedure and documented all abnormalities as well as any incident of clinical significance. An incident was defined as applicable for this study if a monitor would normally be expected to detect it and if it had the potential to cause an important physiological change in a patient during anaesthesia. ${ }^{4}$ The investigator did not notify the attending anaesthetist of any ECG abnormali ties and did not influence anaesthetic management. Standard lead II was monitored in all patients and the instrument was in the "monitor mode" with the filter "on." All ECG monitors had a heart rate indicator triggered by the $R$ wave and an audible beep with adjustable intensity that was turned off in keeping with routine practice so as to avoid confusion with the beep of the pulse oximeter. The ECG alarm limits for heart rate were set at standard defaults (High rate $=120 \cdot \mathrm{min}^{-1}$, low rate $=50 \cdot \mathrm{min}^{-1}$ ). At the end of each case the attending anaesthetist was asked to rate the usefulness of the ECG for that patient on an ordinal scale (useful, of some use and not useful). Usefulness was defined as "ECG information playing a role in decision-making during the anaesthetic."

The sample size was determined on an expected incidence of ECG abnormalities of 5\% with an alpha of 0.05 . A sample size of 350 would have a $99 \%$ power to detect an incidence of ECG abnormalities of $2.8 \%$.

All data were entered onto a spread sheet (Microsoft Excel) and analysed with the Number Cruncher Statistical System, version 5.03. Continuous data were summarised using means $\pm S D$ if normally distributed. Duration of surgery, of sinus tachycardia and of ECG artifact were skewed and were summarised as counts and percentages.

\section{Results}

The ECG was abnormal in $21 \%$ (Table I). The majority of patients underwent therapeutic abortion. The duration of these abnormalities were: sinus tachycardia (HR> 120) $30 \mathrm{sec}$, sinus bradycardia (HR< 60) $17.5 \mathrm{sec}$, artifacts $10 \mathrm{sec}$, leads disconnected for $5 \mathrm{sec}$, and atrial ectopics which lasted $<4$ sec.

Anaesthetic incidents occurred in 10/381 (2.6\%) patients (Table II). Five patients had light anaesthesia, two patients desaturated ( $>5 \%$ decrease in oxygen saturation), one patient developed hypotension (systolic blood pressure $<90 \mathrm{mmHg}$ ), one hiccoughed, and one regurgitated. All intra-operative incidents were detected clinically, by the pulse oximeter or automated blood pressure. The ECG did not detect any of the incidents, and was normal (i.e., heart rate $>60<120$ ) during these events.

Sinus tachycardia was detected in 42 patients $(11 \%)$ and lasted for a median duration of $30 \mathrm{sec}$ (range 5180). Artifacts were detected in 26 patients (7\%) and resulted from incorrect lead placement or patient movement and lasted for a median duration of $10 \mathrm{sec}$ (range 10-45). Premature atrial contractions (PAC) were detected in six patients (1.6\%) and lasted $<5 \mathrm{sec}$. The leads were disconnected in four patients (1\%) which lasted < $90 \mathrm{sec}$. All lead disconnects were noticed by the investigator but not the attending anaestherist and the investigator did not attempt to reconnect the leads. Sinus bradycardia was detected in two patients (0.5\%) and lasted $17.5 \mathrm{sec}$ (range 5-30): PVC's were detected in one patient $(0.3 \%)$ and lasted $<5 \mathrm{sec}$. None of the ECG abnormalities required treatment. 
The ECG was rated as "useful" in $\mathbf{0 . 3 \%}$, of "some use" in $87 \%$ and "not useful" in $12 \%$ of the patients by the attending anaesthetist.

\section{Discussion}

A prospective study in healthy ambulatory patients undergoing short procedures under general anaesthesia demonstrated that ECG monitoring was of limited use in identifying clinically significant problems which occurred in $2.6 \%$ of the patients. Minor ECG abnormalities were detected in $21 \%$ of patients but resolved without treatment within $180 \mathrm{sec}$.

The ECG was the first electronic monitor available for use in anaesthesia. ${ }^{5}$ Perhaps a reflection of this is its widespread use and its endorsement as a routine monitor by the Canadian Anaesthetist's Society and the American Society of Anesthesiologists. ${ }^{1,2}$ The limitations of ECG monitoring are now increasingly being

TABLE I Demographics and ECG abnormalities*

\begin{tabular}{lll}
\hline & & Duration sec \\
\hline Age (yr) & $27 \pm 7(14-40)$ & \\
Weight $(\mathrm{kg})$ & $62(41-107)$ & \\
Duration of surgery $(\mathrm{min})$ & $10(5-25)$ & \\
Surgery type & Therapeutic abortion 333 \\
& Cystoscopy 45 & \\
& Vulval surgery 3 & \\
Sinus Tachycardia $(>120)$ & $41(11 \%)$ & $30(5-180)$ \\
Sinus Bradycardia $(<60)$ & $2(0.5 \%)$ & $17.5(5-30)$ \\
Leads off & $4(1 \%)$ & $5(5-90)$ \\
Artifact & $26(7 \%)$ & $10(10-45)$ \\
PVC & $1(0.3 \%)$ & 1 \\
PAC & $6(1.6 \%)$ & $4(1-5)$ \\
\hline
\end{tabular}

PVC $/ \mathrm{PAC}=$ Paroxysmal ventricular/atrial contraction

* Mean \pm SD if normal; Median (range) if skewed; Categorical data are summarised as count (\%).

TABLE II Intra-operative incidents, mode of detection and usefulness of ECG.

\begin{tabular}{|c|c|c|}
\hline \multicolumn{3}{|l|}{ Complication } \\
\hline Light anaesthesia & $5(1.3 \%)$ & \\
\hline Desaturation & $2(0.5 \%)$ & \\
\hline Regurgitation & $1(0.3 \%)$ & \\
\hline Hiccough & $1(0.3 \%)$ & \\
\hline Hypotension & $1(0.3 \%)$ & \\
\hline Vomiting & $\mathbf{0}$ & \\
\hline Laryngospasm & 0 & \\
\hline Hypertension & $\mathbf{0}$ & \\
\hline Total \# first detected by ECG & $\mathbf{0}$ & \\
\hline \multicolumn{2}{|l|}{ Mode of first detection: } & \\
\hline \multirow[t]{3}{*}{ Usefulness of ECG: } & Not useful & $47(12 \%)$ \\
\hline & Some use & $333(87 \%)$ \\
\hline & Useful & $1(0.3 \%)$ \\
\hline
\end{tabular}

recognised. Major physiological changes, including myocardial ischaemia, can occur during anaesthesia with no change in the ECG signal. 4,6,7

The incidence of arrhythmias in the present study was $13.4 \%$. All resolved spontaneously within $180 \mathrm{sec}$ and were considered to be benign and in keeping with the physiological changes associated with anaesthesia and surgery. This is to be expected because arrhythmias are correlated with clinical events such as induction, intubation, surgical stimuli known to provoke vagal reflexes, deep anaesthesia, succinylcholine administration and airway management. ${ }^{8}$ It is interesting to note that the incidence of arrhythmias in patients aged $<40$ yr was reported as $22 \%$ in the 1960 s but this higher incidence may be due to the widespread use of arrhythmogenic anaesthetics such as halothane, methoxyflurane, ether and cyclopropane. ${ }^{5}$ Subsequently, in 1977 a study of 7,000 anaesthetics demonstrated an overall incidence of arrhythmias of $11 \%{ }^{8}$ However, the incidence of arrhythmias in healthy ASA I patients was only $6.4 \%$ and for procedures $<45 \mathrm{~min}$ it was $8.3 \%$. The authors acknowledged that the importance of these transient arrhythmias in healthy patients was uncertain and questioned the appropriateness of routine ECG monitoring in such patients.

Another approach to help place our findings in the proper perspective is to consider the rate of arrhythmias in unanesthetized healthy patients. Healthy children aged 7-11 yr exhibit heart rates between 37$197 \cdot \mathrm{min}^{-1}$ and junctional rhythms, PACs and PVCs can be identified in $21-45 \% .{ }^{9}$ In healthy medical students heart rates ranged from $37-180 \cdot \mathrm{min}^{-1}$ and the incidence of second-degree AV block, sinus arrests and PVCs was $6 \%, 28 \%$ and $50 \%$ respectively. ${ }^{10}$ Thus, the arrhythmias detected in our healthy outpatients during anaesthesia do not appear quite so ominous. Such considerations have led to suggestions that, for routine anaesthesia in healthy young patients, a pulse monitor or stethoscope will detect the presence of any arrhythmia, and an ECG monitor may then be used for definition of the type. ${ }^{11}$

Recently, it has been demonstrated that intra operative events occur in only $3.65 \%$ of ambulatory patients with an overall rate of 43 per 1000 operations. ${ }^{12}$ The rate of cardiac events was 28 per 1000 surgeries and the frequency of these events per 1000 was: hypertension (15), bradycardia (4), hypotension (3.8), dysrythmia (3.3), tachycardia (0.8) and ischaemia (0.06). Thus, not only are serious cardiac events infrequent in outpatients but the abnormalities can also be detected by other monitors such as the pulse oximeter and automated sphygmomanometer which also provide additional information about the circulatory and respiratory system. ${ }^{4}$ 
In healthy young patients the ECG monitor mainly functions as a heart rate meter. Its ability to characterise arrhythmias is not important because as shown in this and other studies ${ }^{4,5,8,12}$ such arrhythmias are usually evanescent, seldom cause impairment of cardiac output or blood pressure and specific drug treatment is rarely indicated. ${ }^{11}$ The ability to detect myocardial ischaemia is not a consideration in healthy young outpatients. ${ }^{11,12}$ Thus, availability of a pulse oximeter with an audible beep, renders an ECG somewhat redundant in healthy young patients. In fact, theoretical analysis of the AIMS data showed that a pulse oximeter, used on its own would have detected $82 \%$ of incidents (nearly $60 \%$ before any potential for organ damage) and addition of an ECG would have increased the yield by less than $0.5 \% .{ }^{13}$ The ECG detected only 238 of 1256 incidents (19\%) and in $98 \%$ of these incidents the rhythm was an innocuous brady- or tachycardia. ${ }^{13}$

It would be an impossible task to prove that the addition of an ECG improves anaesthetic safety, let alone demonstrate that omitting its use in fit young patients having minor surgery would compromise safety. In the present study, the incidence of ECG abnormalities during adverse events $(0 / 10)$ would have a $95 \%$ confidence limit (CI) of $0-30 \%$. This means that at least 60 adverse events with no ECG abnormalities would have to be demonstrated in order to reduce the CI to $0-5 \%$. Based on our findings, a randomised study is not justifiable because it would require at least 38,000 patients, would be expensive and would yield very little meaningful information. It is estimated that well over 200,000 healthy patients under $35 \mathrm{yr}$ would have to be monitored before encountering one at risk of death. ${ }^{11}$ However, surveys of anaesthetists demonstrate that $80 \%$ would use an ECG for anaesthetising a healthy young patient scheduled for a short procedure. ${ }^{14}$ In the present study, the ECG was rated as "useful" or of "some use" in over $87 \%$ of cases by the attending anaesthetist. The influence of practice guidelines on the behaviour and opinion of anaesthetists cannot be underestimated. One argument in favour of routine ECG monitoring may be that arrhythmias are unpredictable and that ECG-based information may be required in a hurry. However, monitoring guidelines in Australia and New Zealand have now been amended so that ECG is no longer mandatory in all patients but has to be available in the operating room and, to date, there is no published evidence that patient care has been compromised. ${ }^{15} \mathrm{~A}$ review of the CAS and ASA monitoring guidelines may be indicated in the light of the findings of this study. Such a review would be in keeping with the requirements of good guideline development such as validity, reliability, clinical applicability, clinical flexi- bility, clarity, multi-disciplinary developmental process and scheduled review for warranted revision. ${ }^{16}$

In summary, routine ECG monitoring did not detect any intra-operative incidents in healthy adults during short outpatient procedures. All ECG abnormalities detected were innocuous and resolved spontaneously within three minutes. Firm conclusions as to the safety implications of withdrawing ECG monitoring cannot be made from this study. Routine guidelines may need to be reviewed to determine whether ECG monitoring in such cases should be optional rather than mandatory.

\section{References}

1 Guidelines to the practice of anaesthesia. Can J Anaesth 1996; 43(Suppl): 1-9.

2 Kroll $D A$, Cheney $F W$. Medicolegal aspects of anesthesia practice. In: Barash PG, Cullen BF, Stoelting RK (Eds.). Clinical Anesthesia, 2nd ed. Philadelphia: J.B. Lippincott Company, 1992: 115-25.

3 Fragen RJ, Avram MJ. Nonopioid intravenous anesthetics. In: Barash PG, Cullen BF, Stoelting RK (Eds.).

Clinical Anesthesia, 2nd ed. Philadelphia: J.B. Lippincott Company, 1992: 385-412.

4 Ludbrook GL, Russel W, Webb RK, Klepper ID, Currie $M$. The Australian Incident Monitoring Study. The electrocardiograph: applications and limitations - an analysis of 2000 incident reports. Anaesth Intensive Care 1993; 21: 558-64.

5 Russell PH, Coakley CS. Electrocardiographic observation in the operating room. Anesth Analg 1969; 48: 784-8.

6 Knill RL, Gelb AW. Peripheral chemoreceptors during anesthesia. Are the watchdogs sleeping? (Editorial) Anesthesiology 1982; 57: 151-2.

7 Smith J, Calaban $M$, Benefiel $D$, et al. Intra operative detection of myocardial ischaemia at high risk patients: electro cardiographic versus two-dimensional transosophageal echocardiography. Circulation 1985; 72 : 1015-19.

8 Hur D, Gravenstein JS. Is ECG monitoring in the operating room cost effective? Biotelemetry Patient Monitg 1979; 6: 200-6.

9 Soutball DP, Johnston F, Shinebourne EA, Johnstone PG. A 24-hour electro cardiographic study of heart rate and rhythm patterns in population of healthy children. Br Heart J 1981; 45: $281-9$.

10 Brodsky $M, W u D$, Denes $P$, Kanakis $C$, Rosen $K M$. Arrhythmias documented by 24 hour continuous electrocardiographic monitoring in 50 male medical students without apparent heart disease. Am J Cardiol 1977; 39: 390-8. 
11 Tyers MR, Russell WJ, Runciman WB. Electrocardiographic monitoring in anaesthesia. Anesth Intensive Care 1988; 16: 66-9.

12 Chung $F$, Mezei $G$. Intraoperative adverse events during ambulatory surgical procedures. Can J Anaesth 1997; 44: A70-A.

13 Webb RK, Van der Walt JH, Runciman WB, et al. Which monitor? An analysis of 2000 incident reports. Anaesth Intensive Care 1993; 21: 529-42.

14 Pearsall FJ, Davidson JA, Asbury AJ. Attitudes to the Association of Anaesthetists recommendations for standards of monitoring during anaesthesia and recovery. Anaesthesia 1995; 50: 649-53.

15 Australian and New Zealand College of Anaesthetists. Monitoring during anaesthesia. 1995(Oct); Policy document No P 18.

16 Shomaker TS. Practice policies in anesthesia: a foretaste of practice in the 21st century. Anesth Analg 1995; 80: 388-403. 